\title{
МОЛЕКУЛЯРНАЯ ПРИРОДА ГКР-СПЕКТРОВ СУСПЕНЗИИ Е. COLI ПРИ ДЛИНАХ ВОЛН ВОЗБУЖДЕНИЯ 532 И 785 НМ С ИСПОЛЬЗОВАНИЕМ ЗОЛЕЙ НАНОЧАСТИЦ СЕРЕБРА В КАЧЕСТВЕ ГКР-СУБСТРАТОВ
}

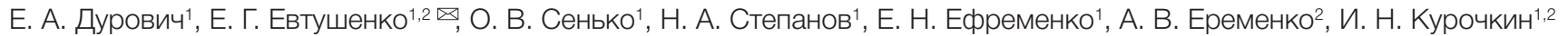

${ }^{1}$ Химический факультет, Московский государственный университет имени М. В. Ломоносова, Москва

2 Институт биохимической физики имени Н. М. Эмануэля РАН, Москва

Вопрос о молекулярной природе спектров гигантского комбинационного рассеяния (ГКР) бактерий является ключевым для оценки перспектив их дискриминации и идентификации данным методом в целях клинической диагностики, обеспечения безопасности пищевых продуктов и др. Ранее было показано, что при использовании в качестве ГКР-субстрата агрегированных и покрытых слоем $\mathrm{SiO}_{2}$ золотых наночастиц на твердой поверхности источником спектра при длине волны возбуждения 785 нм является смесь шести пуриновых производных (аденина, гуанина, АМФ, гипоксантина, ксантина и мочевой кислоты), выделяемая клетками в раствор. Целью настоящей работы было показать применимость данной интерпретации спектров на примере суспензии клетоK Escherichia coli штамма DH5a для другого класса ГКР-субстратов - золей наночастиц серебра при длинах волн возбуждения 785 и 532 нм. Золи получали восстановлением нитрата серебра хлоридом гидроксиламина в щелочной среде, среднечисловой размер частиц составил $43 \pm 2$ нм. Выявлены две важные особенности: во-первых, спектр пуриновых метаболитов регистрируется только при наличии живых клеток; во-вторых, при использовании золей наночастиц серебра в качестве ГКР-субстрата спектрам даже одного и того же штамма присуща значительная вариативность вследствие изменения соотношения концентраций пуриновых метаболитов, выделяемых клетками в раствор.

Ключевые слова: ГКР-спектры бактерий, E. coli, наночастицы серебра, пуриновые производные

$\varangle$ Для корреспонденции: Евгений Геннадиевич Евтушенко

Ленинские горы, д. 1, стр. 3, г. Москва, 119991; evtushenko@enzyme.chem.msu.ru

Статья получена: 15.08.2018 Статья принята к печати: 09.09.2018

DOI: $10.24075 /$ vrgmu.2018.088

\section{MOLECULAR ORIGIN OF SURFACE-ENHANCED RAMAN SPECTRA OF E. COLI SUSPENSIONS EXCITED AT 532 AND 785 NM USING SILVER NANOPARTICLE SOLS AS SERS SUBSTRATES}

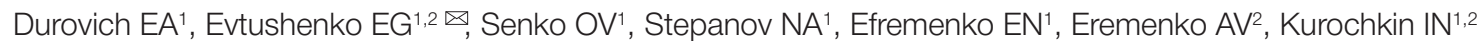 \\ ${ }^{1}$ Faculty of Chemistry, Lomonosov Moscow State University, Moscow, Russia \\ ${ }^{2}$ Emanuel Institute of Biochemical Physics of RAS, Moscow, Russia
}

Research into the molecular origin of surface-enhanced Raman spectra (SERS) of bacteria is a crucial step in assessing the future of SERS-based discrimination and identification of bacteria in clinical analysis, food quality control, etc. Previous studies have revealed that at $785 \mathrm{~nm}$ excitation wavelength SERS of bacterial cells placed on a solid surface functionalized with in-situ grown aggregated gold nanoparticles covered with $\mathrm{SiO}_{2}$ originate from a mixture of 6 purine derivatives (adenine, guanine, AMP, hypoxanthine, xanthine, and uric acid) that are released by the cells into the medium. The aim of the present work was to investigate whether such interpretation is possible with a different class of SERS substrates: silver nanoparticle sols at excitation wavelengths of 785 and $532 \mathrm{~nm}$. The suspension of the Escherichia coli DH5a strain was used as a model bacterium. Sols of silver nanoparticles were obtained by reducing silver nitrate in the presence of alkaline hydroxylamine hydrochloride. Number-weighted mean hydrodynamic diameter of the particles was $43 \pm 2 \mathrm{~nm}$. We confirm that at both excitation wavelengths the spectra can be best described as a superposition of 4 purine derivatives: adenine, guanine, hypoxanthine, and xanthine. Importantly, we have discovered that 1) the spectra of the purine mixture are characteristic of viable cells only; 2) due to the variations in the concentrations of purine metabolites released by the cells into the surrounding medium the spectra of a bacterial strain can vary significantly when a silver nanoparticle sol is used as a SERS substrate.

Keywords: SERS of bacteria, E. coli, silver nanoparticles, purines

$\varangle$ Correspondence should be addressed: Evgeniy G. Evtushenko

Leninskie gory 1, bl. 3, Moscow, 119991; evtushenko@enzyme.chem.msu.ru

Received: 15.08.2018 Accepted: 09.09.2018

DOI: 10.24075/brsmu.2018.088

Явление гигантского комбинационного рассеяния (ГКР), заключающееся в значительном усилении интенсивности полос в спектрах комбинационного рассеяния (KР) при нахождении интересующих молекул вблизи наноструктурированной поверхности металла, в течение последних десятилетий привлекает внимание исследователей, разрабатывающих биоаналитические платсормы и методики. Интерес к данному методу детектирования обусловлен простотой его аппаратного оформления, экспрессностью, возможностью локального анализа, потенциальной мультиплексностью и возможностью достижения высокой чувствительности. Используемые металлические наноструктуры, 
называемые ГКР-субстратами, разделяют на два основных класса: наноструктуры на твердых поверхностях и коллоидные растворы (золи) металлических наночастиц.

Первые ГКР-спектры бактерий с использованием возбуждающего лазера с длиной волны 514,5 нм наблюдали на примере Escherichia coli и Bacillus megaterium [1]. Вскоре было выявлено, что при использовании длин волн возбуждения (ДВВ) 488 и 514,5 нм ГКР-спектры различных грамотрицательных и грамположительных бактерий, а также выделенных клеточных мембран практически не отличаются друг от друга и представляют собой ГКРспектр рибофлавина в восстановленной или окисленной форме [2-4]. Благодаря перекрыванию этих ДВВ с полосой поглощения рибославина реализуются условия резонансного усиления его спектра [3]. Рибофрлавин в форме различных кофакторов окислительновосстановительных ферментов и электрон-транспортных белков локализован в мембранах бактериальных клеток, что обеспечивает его близость к поверхности металла как в случае адсорбции клеток на твердых ГКР-субстратах, так и при адсорбции или синтезе металлических наночастиц на поверхности клеток [3, 4]. С биоаналитической точки зрения это означает, что использование коротковолновых лазеров (488 и 514,5 нм) не позволяет проводить дискриминацию/идентификацию бактерий.

В то же время при использовании длинноволновых источников возбуждения, прежде всего 785 нм, в ГКРспектрах бактериальных клеток отсутствуют характерные полосы рибосрлавина. Более того, спектры разных видов, а в ряде случаев и штаммов бактерий различаются между собой, а также между нативными и инактивированными препаратами одного штамма [5-7]. Этот факт позволил уже в середине 2000-х гг. выдвинуть гипотезу о возможности детектирования и дискриминации бактериальных видов/штаммов на основе их ГКР-спектров при данной ДВВ. Такой подход можно было бы с успехом применять для быстрого обнаружения и типирования патогенных бактерий в клинических образцах, пищевых продуктах, объектах окружающей среды. Однако молекулярная природа регистрируемых спектров на протяжении длительного времени оставалась неясной. По аналогии с коротковолновыми лазерами, предполагалось, что источниками полос служат молекулы, локализованные в клеточной оболочке бактерий: слизистом слое, капсуле, клеточной стенке или мембране. Предложения считать источником полос N-ацетил-D-глюкозамин [6], аминокислотные остатки, пептиды, простетические группы белков, фосфолипиды, метаболиты (например, глюкозу или ацетоуксусную кислоту), ДНК и ее компоненты аденин и гуанин [5, 7-13] были несостоятельны, так как ограничивались интерпретацией отдельных полос, но не всего спектра в целом, что вызывало сомнения в корректности таких предположений. В отсутствие четкой молекулярной интерпретации в данной научной области в течение длительного времени главенствовал формальный математический подход, основанный на снижении размерности экспериментальных данных (спектров) при помощи метода главных компонент с последующим использованием различных модификаций дискриминантного и кластерного анализа с целью демонстрации возможности различать бактерии разных родов, видов или штаммов на основании их ГКР-спектров [6, 12-15].

В 2016 г. было убедительно показано, что источником ГКР-спектров всех 10 исследованных бактериальных препаратов при ДВВ 785 нм являются 6 пуриновых производных (аденин, гуанин, аденозинмонофосфат, гипоксантин, ксантин и мочевая кислота), выделяемых бактериями во внеклеточную среду [16]. Такая интерпретация кардинально сужает применимость ГКРспектров бактерий для их идентификации/дискриминации, поскольку различия в спектрах вызваны не широким разнообразием молекул на поверхности клеток, а всего лишь 6 секретируемыми клетками пуриновыми производными. Было, например, показано, что ГКР-спектр мутанта E. coli c неактивным геном аденозиндезаминазы и, как следствие, не содержащего гипоксантин, гораздо ближе к спектру Staphylococcus aureus, нежели к спектру родительского штамма E. coli. Такие результаты были получены для ДВВ 785 нм и ГКР-субстратов в виде агрегированных золотых наночастиц, нанесенных на твердую поверхность и покрытых тонким слоем диоксида кремния. Целью нашей работы было проверить данные выводы, во-первых, на принципиально ином типе ГКРсубстратов, а именно золях серебряных наночастиц, и, во-вторых, изучить молекулярную природу ГКР-спектров бактерий при ДВВ 532 нм, являющейся промежуточной между областью доминирования рибофлавина (488, 514.5 нм) и инсракрасной областью $(785,1064$ нм).

\section{МАТЕРИАЛЫ И МЕТОДЫ}

В качестве модельного штамма использовали E. coli $\mathrm{DH} 5 \alpha$ (Thermo Fisher Scientific; США). Культивирование клеток проводили на жидкой питательной среде, состоящей из 10,0 г/л триптона (Difco; CШA), 5,0 г/л дрожжевого экстракта (Difco; США), 10,0 г/л NaCl х. ч. (Химмед; Россия) с рH 6,8, при $37^{\circ} \mathrm{C}$ в течение 14-16 ч до начала стационарной фазы роста. В литературе подчеркивается важность тщательной отмывки клеток от компонентов культуральной среды [17], поэтому использовали следующую процедуру: клетки осаждали при 8000 об./мин в течение 7 мин с использованием центрифуги Beckman J-2-21 (Beckman Coulter; США). Осадок отмывали равным объемом 0,9\% раствора $\mathrm{NaCl}$. Процедуру осаждения-промывки повторяли 2 раза. Полученную биомассу разбавляли 0,9\% раствором $\mathrm{NaCl}$ в объеме, необходимом для получения суспензии с концентрацией клеток 1 - $10^{8}$ кл./мл. Концентрацию определяли по мутности суспензии клеток при длине волны 540 нм.

Частичную инактивацию бактерий проводили путем нагрева суспензий клеток при $70^{\circ} \mathrm{C}$ или $90^{\circ} \mathrm{C}$ в течение 1 ч на водяной бане. В качестве показателя степени инактивации измеряли концентрацию внутриклеточного АТФ люциферинлюциферазным методом с использованием набора реагентов и калибровочных стандартов (Люмтек; Россия).

В качестве ГКР-субстрата использовали золь наночастиц серебра (НЧС), получаемый путем восстановления нитрата серебра гидрохлоридом гидроксиламина с использованием $\mathrm{AgNO}_{3}$ ч. д. а. (Sigma-Aldrich; $\mathrm{C} \mathrm{A}$ ), $\mathrm{NH}_{2} \mathrm{OH} \bullet \mathrm{HCl}$ ч (Prime Chemicals Group; Россия), $\mathrm{NaOH}$ ч. д. а. (Мосреактив; Россия). В соответствии с рекомендациями авторов оригинальной методики [18] раствор нитрата серебра приливали к щелочному раствору гидроксиламина, конечные концентрации реагентов в смеси составляли $1 \mathrm{mM} \mathrm{AgNO}, 3,5 \mathrm{mM} \mathrm{NH}_{2} \mathrm{OH} \bullet \mathrm{HCl}, 3 \mathrm{MM} \mathrm{NaOH}$. Полученные золи использовали не более 3 дней с момента получения.

Характеризацию НЧС проводили при помощи регистрации спектров поглощения в УФ-видимой области (300-750 нм) на кюветном спектрофотометре UV-1800 
(Shimadzu; Япония), а также с использованием метода анализа траекторий наночастиц на приборе Nanosight LM10 HS-BF (Nanosight Ltd; Великобритания).

Для всех бактериальных препаратов, как нативных, так и инактивированных, ГКР-спектры регистрировали в день получения препарата. До измерения препарать хранили при $+4{ }^{\circ} \mathrm{C}$. Непосредственно перед измерением аликвоту препарата дважды центрифугировали при 3700 об./мин в течение 5 мин на центрифуге Biofuge A (Heraeus Sepatech; Германия) и промывали равным объемом деионизированной воды. Полученную суспензию клеток в воде смешивали с золем НЧС в соотношении 1 : 1, инкубировали 1 мин и добавляли раствор $\mathrm{NaCl}$ в конечной концентрации 40 мМ для агрегации наночастиц и усиления ГКР-сигнала. Полученный образец в количестве 260 мкл переносили в лунку алюминиевого планшета, использовавшегося для минимизации фонового сигнала и улучшения теплоотвода от измеряемого образца. С каждого образца регистрировали 3-4 повторных спектра, перемешивая образец в лунке пипетированием между измерениями.

При изучении динамики изменения спектров ГКР суспензии E. coli co временем 5 мл препарата были однократно переведены в воду по описанной выше методике. Полученный препарат хранили при $+4{ }^{\circ} \mathrm{C}$ и в течение 4 ч отбирали аликвоты для регистрации ГКР-спектров.

Для получения фильтрата суспензии клеток использовали медленное фильтрование через шприцевую фрильтрующую насадку SFNY030022S (Membrane Solutions; США) диаметром 30 мм и размером пор 0,22 мкм.

Для регистрации спектров КР при ДВВ 785 нм использовали КР-спектрометр innoRam BWS445(B)-785S (BWTek; США) с диапазоном измерения 64-3011 см-1, разрешением $4 \mathrm{~cm}^{-1}$, диодным лазером 785 нм, объективом ×20 PL L 20/0.40. Условия получения спектров: мощность луча на образце - 42 мВт, время накопления сигнала 5 с, количество автоматически усредняемых повторов - 20 . Для регистрации спектров при ДВВ 532 нм использовали KP-спектрометр iRaman BWS415-532S (BWTek; CШA) c диапазоном измерения 174-4001 $\mathrm{cm}^{-1}$, разрешением $4 \mathrm{~cm}^{-1}$, диодным лазером 532 нм, объективом ×20 PL L 20/0.40. Условия получения спектров: мощность луча на образце 20 мВт, время накопления сигнала -5 с, количество автоматически усредняемых повторов - 20.

Обработку полученных спектров проводили с использованием программы OPUS 7.0 (Bruker Optik GmbH; Германия). Обработка включала в себя: выделение области спектра в диапазоне 500-1800 см-1, вычитание базовой линии с использованием встроенного в программу инструмента Background correction. Определение положения и интенсивности полос проводили без дополнительного сглаживания спектров. При графическом представлении спектров их сглаживали инструментом Smooth с использованием рамки шириной $9 \mathrm{~cm}^{-1}$. При необходимости графической демонстрации качественных различий в серии спектров проводили их векторную нормировку, при необходимости сравнения интенсивностей спектров нормировку не использовали.

\section{РЕЗУЛЬТАТЫ ИССЛЕДОВАНИЯ}

Золи НЧС, получаемые гидроксиламиновым методом [18], завоевали широкую популярность в качестве ГКРсубстрата благодаря простоте и воспроизводимости получения, а также высокой интенсивности регистрируемых с их помощью ГКР-спектров различных аналитов, в том числе бактериальных клеток [19-21]. Полученные нами препараты золей НЧС имеют желто-коричневый цвет, прозрачны и не содержат осадка. Они демонстрируют интенсивную широкую полосу поглощения в ближней УФ синей области, соответствующую локализованному плазмонному резонансу НЧС с максимумом при 407-409 нм и поглощением в максимуме, меняющемся в пределах от 16,5 до 18 (с учетом разведения деионизованной водой в 30 раз при измерении). Среднечисловой гидродинамический диаметр частиц, измеренный методом анализа траекторий наночастиц для трех независимых партий НЧС, составил $43 \pm 2$ нм; суммарная концентрация частиц равна (8,0 \pm $1,7) \cdot 10^{11}$ частиц/мл. Полученные золи НЧС при агрегации раствором $40 \mathrm{mM} \mathrm{NaCl}$ не имеют собственного ГКРспектра при обоих значениях ДВВ, за исключением широкой низкоинтенсивной полосы материала планшета (алюминия) в области 1200-1700 см-1. Эту полосу можно полностью удалить в виде базовой линии при обработке спектров.

Для изучения повторяемости ГКР-спектров нативных E. coli при ДВВ 785 нм были проведены: а) повторные измерения одного и того же образца, подготовленного для ГКР из одной аликвоты суспензии бактерий; б) измерения разных аликвот одного и того же препарата бактерий как с одним и тем же препаратом НЧС, так и с разными; в) измерения независимо культивированных и выделенных препаратов E. coli с одним и тем же препаратом наночастиц. В целом, измерения одного и того же бактериального препарата демонстрируют хорошую повторяемость (рис. 1А). В то же время ГКР-спектры независимых бактериальных препаратов подвержены значительным вариациям (рис. 1Б). Наибольшие различия наблюдаются в областях: 508-532, 655, 730-734, 958, 1450, 1570-1576 см-1.

При исследовании динамики изменения ГКР-спектров E. coli при хранении в воде при $+4{ }^{\circ} \mathrm{C}$ на временном интервале 4 ч (рис. 1В) с течением времени наблюдали медленный рост общей интенсивности спектра с изменением соотношения интенсивностей отдельных полос. Например, отношение $\mathrm{I}_{730} / \mathrm{I}_{655}=1,2$ оставалось постоянным для всех значений времен, а отношение $\mathrm{I}_{1325} / \mathrm{I}_{655}$ монотонно снижалось от начального значения, равного 1,6, до 1,0 при 4 ч хранения.

С целью изучения локализации молекул, ответственных за формирование ГКР-спектров, было проведено сравнение ГКР-спектра нативного препарата E. coli в воде с фильтратом (0,22 мкм) того же препарата (рис. 1Г). Учитывая продемонстрированные ранее медленные изменения, спектры аликвот исходной суспензии клеток были зарегистрированы по времени как до, так и после проведения фильтрования и регистрации спектров фильтрата. Все полосы спектра клеточной суспензии присутствовали и в спектре фильтрата. Более того, общая интенсивность спектра фильтрата была значимо выше.

Для ответа на вопрос, являются ли наблюдаемые ГКР-спектры признаком наличия жизнеспособных клеток E. coli или для их появления достаточно инактивированной бактериальной биомассы, было проведено сравнение ГКР-спектров нативных клеток и инактивированных нагреванием при $70^{\circ} \mathrm{C}$ или $90^{\circ} \mathrm{C}$ в течение 60 мин (рис. 2). Для всех трех препаратов была также измерена остаточная концентрация внутриклеточного АТФ, отражающая уровень жизнеспособности клеток. Она составила 1 • 10-9, 5,6 • 10-12 и 4,1 • 10-12 моль на 1 мл суспензии клеток (для исходного препарата, $70{ }^{\circ} \mathrm{C}$ и $90^{\circ} \mathrm{C}$ соответственно). В целом, как и 
для разных партий бактерий, наблюдались значительные вариации числа и положения полос. Однако можно отметить тенденцию к снижению общей интенсивности спектра. Для практически полностью инактивированного препарата $\left(90{ }^{\circ} \mathrm{C}\right)$ в спектре присутствовали лишь четыре полосы нативных E. coli крайне низкой интенсивности

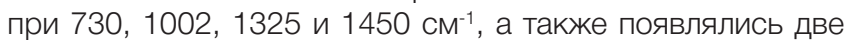
низкоинтенсивные полосы амид III (1230-1270 см-1) и амид I (1640-1680 $\left.\mathrm{CM}^{-1}\right)$.
Эксперименты по изучению повторяемости регистрации ГКР-спектров нативных препаратов E. coli были также проведены с использованием ДВВ, равной 532 нм. Необходимо отметить примерно в 2 раза более высокую интенсивность спектров при ДВВ 532 нм по сравнению с ДВВ 785 нм, что приводит к увеличению числа информативных полос и точности определения их положения. Так же как и в случае с ДВВ 785 нм, при 532 нм наблюдается высокая повторяемость спектров одной и

Таблица. Перечень всех наблюдаемых полос в ГКР-спектрах E. coli, включая фильтраты клеточных суспензий, и их отнесение в соответствии со спектрами пуриновых производных, приведенными в более ранней работе [16]. А — аденин, Г — гуанин, ГК — гипоксантин, Кс — ксантин

\begin{tabular}{|c|c|c|c|c|}
\hline \multicolumn{2}{|c|}{785 нм } & \multicolumn{2}{|c|}{532 нм } & \multirow[b]{2}{*}{ Отнесение } \\
\hline Положение полосы, см ${ }^{-1}$ & $\begin{array}{c}\text { Частота встречаемости в } \\
\text { спектрах, \% }\end{array}$ & Положение полосы, см-1 & $\begin{array}{c}\text { Частота встречаемости } \\
\text { в спектрах, \% }\end{array}$ & \\
\hline $502-515$ & 75 & $502-512$ & 50 & $\mathrm{Kc}, \Gamma$ \\
\hline \multirow{2}{*}{$522-540$} & \multirow{2}{*}{100} & 526 & 75 & $\Gamma$ \\
\hline & & $549-550$ & 25 & $\Gamma \mathrm{K}, \mathrm{A}$ \\
\hline $561-574$ & 100 & & & Kc, Г, A \\
\hline $621-633$ & 50 & 617-623 (sh) & 100 & ГК, А, Г \\
\hline $653-667$ & 100 & $648-651$ & 100 & Г, Kc, A \\
\hline $680-683$ & 38 & & & $\mathrm{Kc}, \mathrm{A}$ \\
\hline $724-735$ & 100 & $721-728$ & 100 & A, ГK \\
\hline \multirow[t]{2}{*}{$780-792$} & 63 & 770 & 25 & $\Gamma \mathrm{K}$ \\
\hline & & 788 & 25 & A \\
\hline \multirow{2}{*}{ 838-842 } & \multirow{2}{*}{38} & 833 & 25 & \multirow{2}{*}{ Тирозин (?) } \\
\hline & & $848-850$ & 50 & \\
\hline $867-883$ & 63 & $875-878$ & 25 & Г, Кc \\
\hline $925-930$ & 38 & & & $\Gamma \mathrm{K}$ \\
\hline 958-966 & 100 & $952-955$ & 100 & Кс, Г, ГК, А \\
\hline $1002-1008$ & 88 & 1000-1006 & 100 & $\begin{array}{c}\text { Фенилаланин (?), } \\
\text { взаимодействие А + ГК + Kc (?) }\end{array}$ \\
\hline \multirow[t]{2}{*}{ 1027-1033 } & 25 & $1024-1027$ & 100 & Г, А, ГК \\
\hline & & $1043-1045$ & 75 & Г, Кс \\
\hline 1084-1096 & 50 & 1085-1095 & 100 & $\Gamma \mathrm{K}$ \\
\hline $1115-1130$ & 38 & $1129-1140$ & 100 & Kc, Г, A \\
\hline $1157-1160$ & 25 & 1154 & 25 & $\Gamma \mathrm{k}$ \\
\hline $1175-1189$ & 63 & & & $\Gamma, \mathrm{A}$ \\
\hline $1213-1215$ & 25 & $1215-1233$ & 100 & Г, ГК, А \\
\hline $1245-1251$ & 50 & 1242 & 25 & $\mathrm{Kc}$ \\
\hline $1267-1276$ & 25 & 1276 & 25 & $\Gamma, \mathrm{A}$ \\
\hline 1310-1315 & 25 & & & $\mathrm{Kc}, \mathrm{A}$ \\
\hline \multirow{2}{*}{$1324-1334$} & \multirow{2}{*}{63} & $1322-1325$ & 75 & $\Gamma \kappa$ \\
\hline & & $1330-1331$ & 50 & $\Gamma \mathrm{K}$ \\
\hline & & 1341 & 25 & A \\
\hline $1362-1380$ & 63 & $1371-1379$ & 100 & Г, Кс, ГК, А \\
\hline $1389-1390$ & 13 & 1399 & 25 & $\mathrm{Kc}$, ГK \\
\hline $1444-1453$ & 88 & 1444 & 25 & ГК, Г, А \\
\hline $1464-1473$ & 75 & $1457-1468$ & 100 & Гк, Г, Кс, A \\
\hline 1508 & 13 & 1506 & 25 & Взаимодействие А + Гк + Кс (?) \\
\hline 1528-1534 & 25 & $1532-1538$ & 100 & Г, ГК, К \\
\hline 1568-1578 & 63 & $1567-1575$ & 50 & Г, А \\
\hline $1582-1591$ & 25 & 1584-1595 & 25 & Kc, ГK \\
\hline \multirow[b]{2}{*}{ 1630-1721 (широкая) } & \multirow[b]{2}{*}{75} & 1646 & 25 & $\Gamma, \mathrm{A}$ \\
\hline & & $1692-1698$ & 100 & Кс, Гк, Г \\
\hline
\end{tabular}


той же аликвоты и одного и того же препарата бактерий (рис. ЗА). Но ГКР-спектры независимо культивированных и выделенных партий бактерий тоже демонстрируют значительную вариативность (рис. ЗБ).

\section{ОБСУЖДЕНИЕ РЕЗУЛЬТАТОВ}

Результаты экспериментов при ДВВ 785 нм по повторяемости и динамике изменения ГКР-спектров E. coli при хранении в воде свидетельствуют о том, что формирование спектров определяет не индивидуальное соединение, а смесь небольшого числа компонентов, так как вся совокупность зарегистрированных спектров содержит лишь фиксированный набор полос (см. таблицу). Соотношения компонентов в данной смеси медленно меняются при хранении клеток в воде (рис. 1В) и значительно различаются для независимо культивированных нативных препаратов (рис. 1Б). Сравнение спектров нативного препарата и его фильтрата (рис. 1Г) свидетельствует о том, что данная смесь соединений не связана с поверхностью клеток, а присутствует в растворе. Более того, значимое повышение общей интенсивности спектра фильтрата по сравнению со спектром суспензии клеток позволяет предположить, что с точки зрения ГКР-регистрации клетки являются мешающим компонентом, например, за счет адсорбции доли частиц на их поверхности.

Эксперименты по инактивации клеток демонстрируют, что данная смесь соединений связана с уровнем жизнеспособности клеток (рис. 2), не являясь продуктом пассивной десорбции веществ с поверхности инактивированных клеток.

В таблице представлен перечень полос, наблюдавшихся во всех ГКР-спектрах нативных препаратов E. coli, включая эксперименты по фильтрованию клеток. Проанализировав различные варианты отнесения полос, описанные в литературе, мы пришли к выводу, что при ДВВ 785 нм практически все полосы можно приписать суперпозиции спектров 4 пуриновых производных (аденина, гуанина, гипоксантина и ксантина) в полном соответствии с выводами, сделанными в более ранней работе [16]. Кроме того, каждый отдельный ГКР-спектр соответствует суперпозиции сигналов этих соединений как по положению полос, так и по их интенсивности (рис. 4A). С учетом возможных небольших различий в относительных интенсивностях полос, связанных с различием ГКР-субстратов (в настоящей работе спектры получены с использованием золей НЧС, в референсной работе [16] - на агрегированных золотых наночастицах), а также сложения интенсивности при наложении полос отдельных соединений, качество описания является высоким. Не отнесенными остаются лишь три полосы низкой интенсивности: 838-842, 1002-1008 и 1508 см$^{-1}$. С одной стороны, можно предположить, что низкоинтенсивные полосы были потеряны при оцифровке спектров из литературных источников. С другой стороны, если данные полосы действительно не присутствуют в спектрах пуриновых производных, можно выдвинуть два предположения относительно их природы. Во-первых,

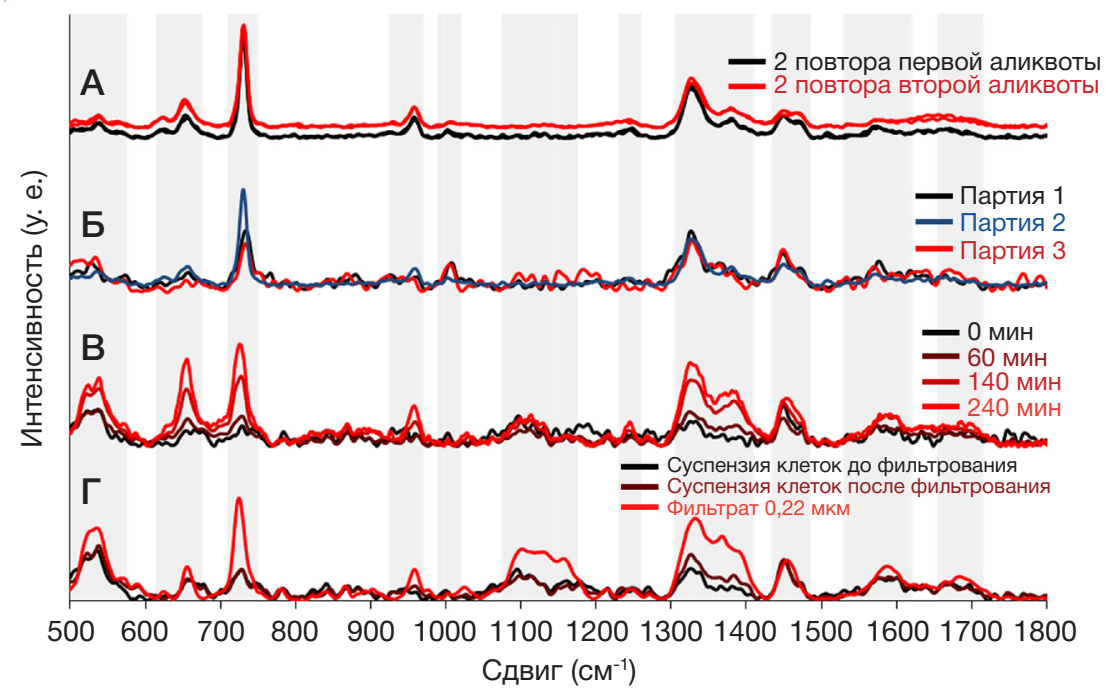

Рис. 1. ГКР-спектры суспензий Е. coli при длине волны возбуждения 785 нм. А. Повторяемость измерений одной аликвоты и одной партии клеток. Б. Повторяемость спектров для независимых партий клеточных суспензий. В. Изменение спектров при хранении клеток в воде при +4 ${ }^{\circ} \mathrm{C}$. Г. Сравнение спектров клеточной суспензии и фильтрата 0,22 мкм той же клеточной суспензии. Спектры (А, Б) векторно нормированы между собой, спектры (В, Г) для демонстрации различий в интенсивности не были нормированы. Серым фоном выделены области различий

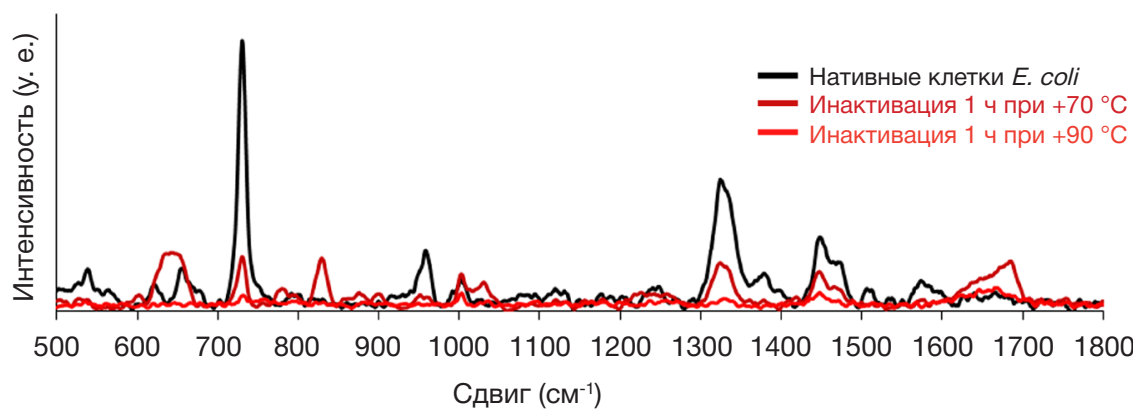

Рис. 2. Изменение ГКР-спектров суспензий E. coli (785 нм) при инактивации клеток нагреванием. Для демонстрации различий в интенсивности спектры не были нормированы между собой 


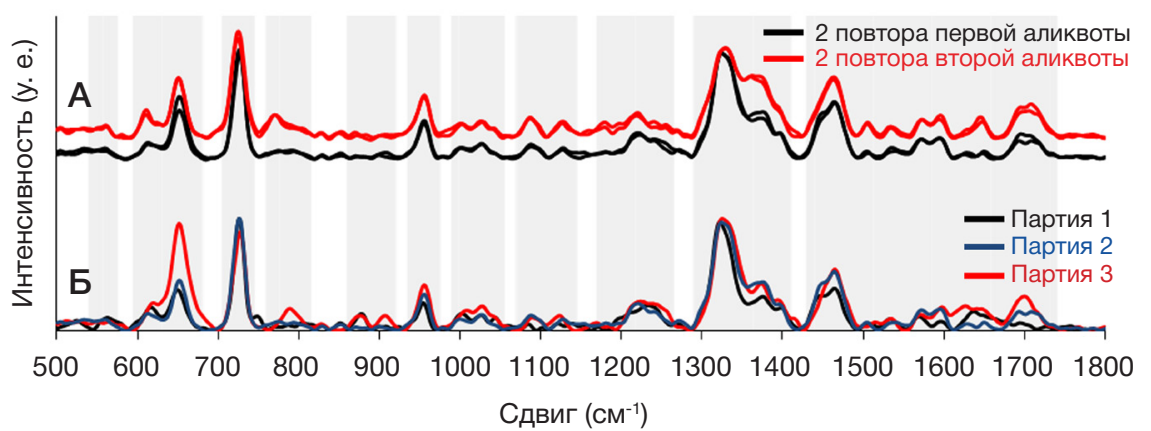

Рис. 3. ГКР-спектры суспензий Е. coli при длине волны возбуждения 532 нм. А. Повторяемость измерений одной аликвоты и одной партии клеток. Б. Повторяемость спектров для независимых партий клеточных суспензий. Спектры векторно нормированы между собой. Серым фоном выделены области различий

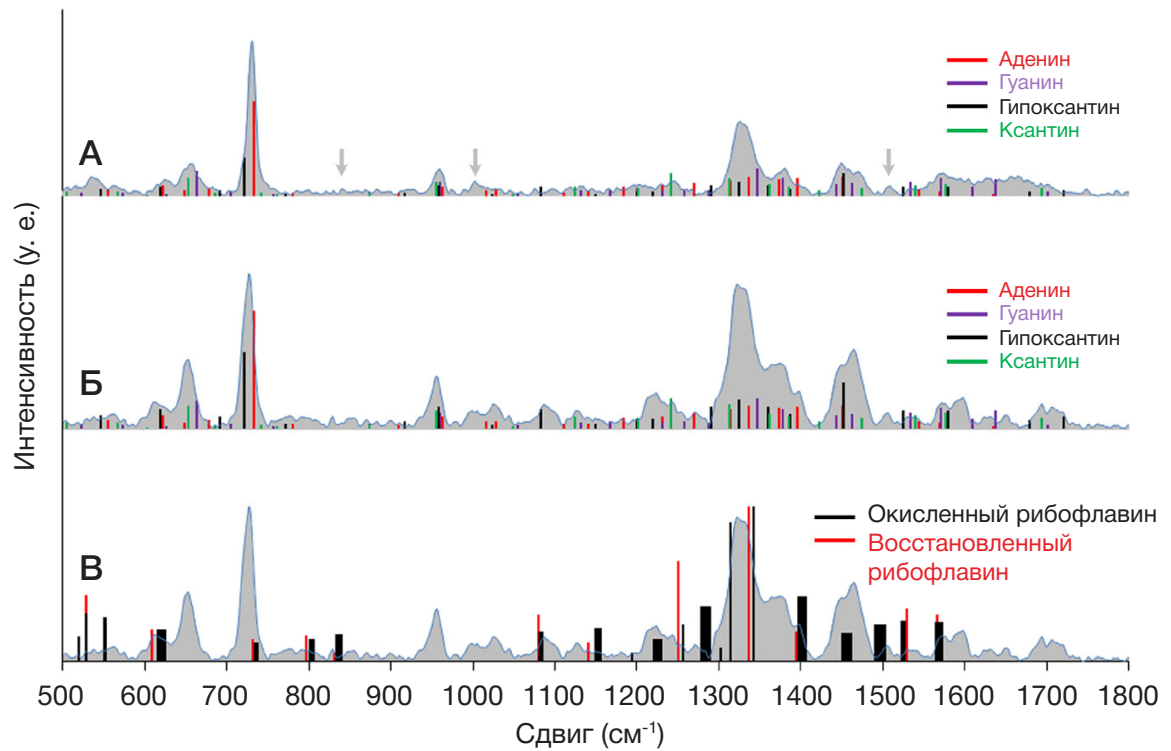

Рис. 4. Наложение полос пуриновых производных [16] и рибосрлавина $[4,24,25]$ на ГКР-спектры суспензий E. coli. А. Наложение полос пуриновых производных на спектр Е. coli при длине волны возбуждения 785 нм. Стрелками помечены не отнесенные низкоинтенсивные полосы. Б. Наложение полос пуриновых производных на спектр E. coli при длине волны возбуждения 532 нм. В. Наложение полос рибофлавина на спектр E. соli при длине волны возбуждения 532 нм. Ширина полос рибофлавина на графике отражает вариации в их положении между данными литературных источников

полосы могут появляться вследствие взаимодействий между компонентами смеси. Например, известен ГКР-спектр смеси аденина, гипоксантина и ксантина, содержащий полосы при 1000 и $1510 \mathrm{~cm}^{-1}$, отсутствующие в спектрах индивидуальных соединений [22]. Кроме того, наличие полос при 838-842 и 1002 см $^{-1}$ можно объяснить наличием минорных количеств тирозина (наиболее интенсивные полосы 824, 847, 928, 1046, 1389 и 1583 см$^{-1}$ [23]) и фенилаланина (наиболее интенсивные полосы 930, 1002, 1031, 1394 и $1602 \mathrm{~cm}^{-1}$ [23]).

Отнесение полос к смеси пуриновых производных объясняет экспериментально наблюдаемую значительную вариацию в положении максимума некоторых полос в спектрах E. coli. Вариация положения максимума широкой многокомпонентной полосы при 502-574 см-1 может быть объяснена наложением полос $508 \mathrm{~cm}^{-1}$ ксантина, $526 \mathrm{~cm}^{-1}$ гуанина, $550 \mathrm{~cm}^{-1}$ гипоксантина, $558 \mathrm{~cm}^{-1}$ аденина и $577 \mathrm{~cm}^{-1}$ гуанина; полосы при 653-667 $\mathrm{cm}^{-1}$ - наложением полос $652 \mathrm{~cm}^{-1}$ аденина, $657 \mathrm{~cm}^{-1}$ ксантина и $667 \mathrm{~cm}^{-1}$ гуанина; полосы при 724-735 $\mathrm{cm}^{-1}$ - наложением полос $725 \mathrm{~cm}^{-1}$ гипоксантина и $734 \mathrm{~cm}^{-1}$ аденина; широкой двойной полосы с максимумами при 1444-1452 см-1 и 1464-1473 см-1 наложением полос $1447 \mathrm{~cm}^{-1}$ гуанина, $1455 \mathrm{~cm}^{-1}$ аденина, $1456 \mathrm{~cm}^{-1}$ гипоксантина, $1466 \mathrm{~cm}^{-1}$ гуанина и $1478 \mathrm{~cm}^{-1}$ ксантина.

Спектры E. coli при ДВВ 532 нм демонстрируют значительное сходство со спектрами при ДВВ 785 нм (рис. 4А, 4Б). В них наблюдаются вариации положения и интенсивности тех же полос, что и при ДВВ 785 нм (рис. 1Б, ЗБ). В связи с этим мы опробовали вариант описания их в виде смеси тех же четырех пуриновых производных (аденина, гуанина, гипоксантина и ксантина). Учитывая, что в данном случае их референсные спектры, описанные ранее [16], отличаются от спектров E. coli не только типом ГКР-субстрата, но и ДВВ, что зачастую приводит к небольшим сдвигам положения полос, качество описания экспериментальных спектров E. coli можно назвать высоким.

Нами была также изучена возможность отнесения полос в спектрах E. coli при ДВВ 532 нм к окисленной или восстановленной формам рибофлавина или ФАД, референсные спектры которых были взяты из более ранних работ $[4,24,25]$ (рис. 4В). В спектрах рибофрлавина отсутствует ряд полос высокой и средней интенсивности спектров E. coli: 650, 725-733, 955, $1365 \mathrm{~cm}^{-1}$, а в спектрах E. coli отсутствует или имеет значительно отличающуюся относительную интенсивность ряд полос рибофлавина: 528-529, 834-839, 1149-1156, 1279-1289, 1491-1502, 1523-1527 см-1 для окисленной формы и 528, 1251, 1501 и 1530 см$^{-1}$ для восстановленной формы. Нельзя полностью исключать наличие небольшого вклада спектра рибофлавина в спектры E. coli при ДВВ 532 нм, это могло бы дополнительно повысить интенсивность широкой 
полосы при 1300-1350 см-1 по сравнению со смесью пуриновых производных. Однако рибофлавин однозначно не является доминирующим соединением в спектре. Это в некоторой степени противоречит сделанным ранее выводам о том, что в спектрах бактерий Pseudomonas aeruginosa, Bacillus subtilis и Geobacillus stearothermophilus при ДВВ 532 нм доминируют полосы рибофрлавина [25]. Данное несоответствие может быть объяснено различиями в используемых видах бактерий.

Таким образом, и при ДВВ 532 нм ГКР-спектры E. coli наилучшим образом можно описать суперпозицией спектров пуриновых производных. Аналогично ДВВ 785 нм, вариативность спектров между бактериальными препаратами разных партий объясняется различными соотношениями концентраций этих соединений, выделяемых клетками в раствор.

\section{Литература}

1. Efrima S, Bronk BV. Silver Colloids Impregnating or Coating Bacteria. J Phys Chem B. 1998; 102 (31): 5947-50.

2. Zeiri L, Bronk BV, Shabtai Y, Czégé J, Efrima S. Silver metal induced surface enhanced Raman of bacteria. Colloids Surfaces A Physicochem Eng Asp. 2002; 208 (1): 357-62.

3. Picorel R, Lu T, Holt RE, Cotton TM, Seibert M. Surface-Enhanced Resonance Raman Scattering (SERRS) Spectroscopy of Bacterial Membranes: The Flavoproteins. In: Baltscheffsky $M$, editor Current Research in Photosynthesis: Proceedings of the VIllth International Conference on Photosynthesis; 1989 Aug 6-11; Stockholm, Sweden. Dordrecht: Springer Netherlands, 1990; p. 1867-70.

4. Zeiri L, Bronk BV, Shabtai Y, Eichler J, Efrima S. Surface-Enhanced Raman Spectroscopy as a Tool for Probing Specific Biochemical Components in Bacteria. Appl Spectrosc. 2004; 58 (1): 33-40.

5. Guzelian AA, Sylvia JM, Janni JA, Clauson SL, Spencer KM. SERS of whole-cell bacteria and trace levels of biological molecules. Proc. SPIE, Vibrational Spectroscopy-Based Sensor Systems. 2002; (4577): 183-92.

6. Jarvis RM, Goodacre R. Discrimination of Bacteria Using SurfaceEnhanced Raman Spectroscopy. Anal Chem. 2004; 76 (1): 40-7.

7. Premasiri WR, Moir DT, Klempner MS, Krieger N, Jones G, Ziegler LD. Characterization of the Surface Enhanced Raman Scattering (SERS) of Bacteria. J Phys Chem B. 2005; 109 (1): 312-20.

8. Luo BS, Lin M. A Portable Raman System for the Identification of Foodborne Pathogenic Bacteria. J Rapid Methods Autom Microbiol. 2008; 16 (3): 238-55.

9. Kahraman M, Keseroğlu K, Çulha M. On sample preparation for surface-enhanced Raman scattering (SERS) of bacteria and the source of spectral features of the spectra. Appl Spectrosc. 2011; 65 (5): 500-6.

10. Feng J, de la Fuente-Núñez C, Trimble MJ, Xu J, Hancock REW, Lu X. An in situ Raman spectroscopy-based microfluidic "lab-on-a-chip" platform for non-destructive and continuous characterization of Pseudomonas aeruginosa biofilms. Chem Commun. 2015; 51 (43): 8966-9.

11. Su L, Zhang P, Zheng D, Wang Y, Zhong R. Rapid detection of Escherichia coli and Salmonella typhimurium by surface-enhanced Raman scattering. Optoelectron Lett. 2015; 11 (2): 157-160.

12. Mosier-Boss AP. Review on SERS of Bacteria. Biosensors. 2017; 7 (4): 51-76.

13. Witkowska E, Korsak D, Kowalska A, Janeczek A, Kamińska A. Strain-level typing and identification of bacteria - a novel approach for SERS active plasmonic nanostructures. Anal Bioanal Chem. 2018; 410 (20): 5019-31.

\section{ВЫВОДЫ}

При использовании в качестве ГКР-субстратов золей наночастиц серебра, полученных гидроксиламиновым методом, источником ГКР-спектров E. coli при ДВВ 785 и 532 нм является смесь пуриновых производных, выделяемых клетками в раствор. Наилучшее описание спектра соответствует четырем соединениям (аденин, гуанин, гипоксантин и ксантин), при ДВВ 532 нм мы не исключаем возможность наличия небольшого вклада рибофлавина. Спектры такого типа проявляются только в присутствии живых бактериальных клеток; им присуща значительная вариативность, обусловленная различиями в соотношениях перечисленных компонентов. Такая молекулярная природа ГКР-спектров бактерий в значительной мере сужает перспективы использования ГКР для целей их дискриминации/идентификации.

14. Patel IS, Premasiri WR, Moir DT, Ziegler LD. Barcoding bacterial cells: a SERS-based methodology for pathogen identification. J Raman Spectrosc. 2008; 39 (11): 1660-72.

15. Sundaram J, Park B, Hinton A, Lawrence KC, Kwon Y. Detection and differentiation of Salmonella serotypes using surface enhanced Raman scattering (SERS) technique. J Food Meas Charact. 2013; 7 (1): 1-12.

16. Premasiri WR, Lee JC, Sauer-Budge A, Théberge R, Costello CE, Ziegler LD. The biochemical origins of the surface-enhanced Raman spectra of bacteria: a metabolomics profiling by SERS. Anal Bioanal Chem. 2016; 408 (17): 4631-47.

17. Marotta NE, Bottomley LA. Surface-Enhanced Raman Scattering of Bacterial Cell Culture Growth Media. Appl Spectrosc. 2010; 64 (6): 601-6.

18. Leopold N, Lendl B. A New Method for Fast Preparation of Highly Surface-Enhanced Raman Scattering (SERS) Active Silver Colloids at Room Temperature by Reduction of Silver Nitrate with Hydroxylamine Hydrochloride. J Phys Chem B. 2003; 107 (24): 5723-7.

19. Cañamares MV, Garcia-Ramos JV, Sanchez-Cortes S, Castillejo M, Oujja M. Comparative SERS effectiveness of silver nanoparticles prepared by different methods: A study of the enhancement factor and the interfacial properties. J Colloid Interface Sci. 2008; 326 (1): 103-9.

20. Knauer M, Ivleva NP, Niessner R, Haisch C. Optimized Surface-enhanced Raman Scattering (SERS) Colloids for the Characterization of Microorganisms. Anal Sci. 2010; 26 (7): 761-6.

21. Félix-Rivera H, González R, Rodríguez GDM, Primera-Pedrozo OM, Ríos-Velázquez C, Hernández-Rivera SP. Improving SERS Detection of Bacillus thuringiensis Using Silver Nanoparticles Reduced with Hydroxylamine and with Citrate Capped Borohydride. Int J Spectrosc. 2011; Article ID 989504.

22. Ranc V, Hruzikova J, Maitner K, Prucek R, Milde D, Kvítek L. Quantification of purine basis in their mixtures at femto-molar concentration levels using FT-SERS. J Raman Spectrosc. 2011; 43 (8): 971-6.

23. Kim SK, Kim MS, Suh SW. Surface-enhanced Raman scattering (SERS) of aromatic amino acids and their glycyl dipeptides in silver sol. J Raman Spectrosc. 1987; 18 (3): 171-5.

24. Kazanci M, Schulte JP, Douglas C, Fratzl P, Pink D, SmithPalmer T. Tuning the Surface-Enhanced Raman Scattering Effect to Different Molecular Groups by Switching the Silver Colloid Solution pH. Appl Spectrosc. 2009; 63 (2): 214-3.

25. Smith-Palmer T, Douglas C, Fredericks P. Rationalizing the SER spectra of bacteria. Vib Spectrosc. 2010; 53 (1): 103-6. 
1. Efrima S, Bronk BV. Silver Colloids Impregnating or Coating Bacteria. J Phys Chem B. 1998; 102 (31): 5947-50.

2. Zeiri L, Bronk BV, Shabtai Y, Czégé J, Efrima S. Silver metal induced surface enhanced Raman of bacteria. Colloids Surfaces A Physicochem Eng Asp. 2002; 208 (1): 357-62.

3. Picorel R, Lu T, Holt RE, Cotton TM, Seibert M. Surface-Enhanced Resonance Raman Scattering (SERRS) Spectroscopy of Bacterial Membranes: The Flavoproteins. In: Baltscheffsky $M$, editor. Current Research in Photosynthesis: Proceedings of the VIllth International Conference on Photosynthesis; 1989 Aug 6-11; Stockholm, Sweden. Dordrecht: Springer Netherlands, 1990; p. 1867-70.

4. Zeiri L, Bronk BV, Shabtai Y, Eichler J, Efrima S. Surface-Enhanced Raman Spectroscopy as a Tool for Probing Specific Biochemical Components in Bacteria. Appl Spectrosc. 2004; 58 (1): 33-40.

5. Guzelian AA, Sylvia JM, Janni JA, Clauson SL, Spencer KM. SERS of whole-cell bacteria and trace levels of biological molecules. Proc. SPIE, Vibrational Spectroscopy-Based Sensor Systems. 2002; (4577): 183-92.

6. Jarvis RM, Goodacre R. Discrimination of Bacteria Using SurfaceEnhanced Raman Spectroscopy. Anal Chem. 2004; 76 (1): 40-7.

7. Premasiri WR, Moir DT, Klempner MS, Krieger N, Jones G, Ziegler LD. Characterization of the Surface Enhanced Raman Scattering (SERS) of Bacteria. J Phys Chem B. 2005; 109 (1): 312-20.

8. Luo BS, Lin M. A Portable Raman System for the Identification of Foodborne Pathogenic Bacteria. J Rapid Methods Autom Microbiol. 2008; 16 (3): 238-55.

9. Kahraman M, Keseroğlu K, Çulha M. On sample preparation for surface-enhanced Raman scattering (SERS) of bacteria and the source of spectral features of the spectra. Appl Spectrosc. 2011; 65 (5): 500-6.

10. Feng J, de la Fuente-Núñez C, Trimble MJ, Xu J, Hancock REW, Lu X. An in situ Raman spectroscopy-based microfluidic "lab-on-a-chip" platform for non-destructive and continuous characterization of Pseudomonas aeruginosa biofilms. Chem Commun. 2015; 51 (43): 8966-9.

11. Su L, Zhang P, Zheng D, Wang Y, Zhong R. Rapid detection of Escherichia coli and Salmonella typhimurium by surface-enhanced Raman scattering. Optoelectron Lett. 2015; 11 (2): 157-160.

12. Mosier-Boss AP. Review on SERS of Bacteria. Biosensors. 2017; 7 (4): 51-76.

13. Witkowska E, Korsak D, Kowalska A, Janeczek A, Kamińska A. Strain-level typing and identification of bacteria - a novel approach for SERS active plasmonic nanostructures. Anal Bioanal Chem. 2018; 410 (20): 5019-31.
14. Patel IS, Premasiri WR, Moir DT, Ziegler LD. Barcoding bacterial cells: a SERS-based methodology for pathogen identification. J Raman Spectrosc. 2008; 39 (11): 1660-72.

15. Sundaram J, Park B, Hinton A, Lawrence KC, Kwon Y. Detection and differentiation of Salmonella serotypes using surface enhanced Raman scattering (SERS) technique. J Food Meas Charact. 2013; 7 (1): 1-12.

16. Premasiri WR, Lee JC, Sauer-Budge A, Théberge R, Costello $\mathrm{CE}$, Ziegler LD. The biochemical origins of the surface-enhanced Raman spectra of bacteria: a metabolomics profiling by SERS. Anal Bioanal Chem. 2016; 408 (17): 4631-47.

17. Marotta NE, Bottomley LA. Surface-Enhanced Raman Scattering of Bacterial Cell Culture Growth Media. Appl Spectrosc. 2010; 64 (6): 601-6.

18. Leopold N, Lendl B. A New Method for Fast Preparation of Highly Surface-Enhanced Raman Scattering (SERS) Active Silver Colloids at Room Temperature by Reduction of Silver Nitrate with Hydroxylamine Hydrochloride. J Phys Chem B. 2003; 107 (24): 5723-7.

19. Cañamares MV, Garcia-Ramos JV, Sanchez-Cortes S, Castillejo M, Oujja M. Comparative SERS effectiveness of silver nanoparticles prepared by different methods: A study of the enhancement factor and the interfacial properties. J Colloid Interface Sci. 2008; 326 (1): 103-9.

20. Knauer M, Ivleva NP, Niessner R, Haisch C. Optimized Surface-enhanced Raman Scattering (SERS) Colloids for the Characterization of Microorganisms. Anal Sci. 2010; 26 (7): 761-6.

21. Félix-Rivera H, González R, Rodríguez GDM, Primera-Pedrozo OM, Ríos-Velázquez C, Hernández-Rivera SP. Improving SERS Detection of Bacillus thuringiensis Using Silver Nanoparticles Reduced with Hydroxylamine and with Citrate Capped Borohydride. Int J Spectrosc. 2011; Article ID 989504.

22. Ranc V, Hruzikova J, Maitner K, Prucek R, Milde D, Kvítek L. Quantification of purine basis in their mixtures at femto-molar concentration levels using FT-SERS. J Raman Spectrosc. 2011; 43 (8): 971-6.

23. Kim SK, Kim MS, Suh SW. Surface-enhanced Raman scattering (SERS) of aromatic amino acids and their glycyl dipeptides in silver sol. J Raman Spectrosc. 1987; 18 (3): 171-5.

24. Kazanci M, Schulte JP, Douglas C, Fratzl P, Pink D, SmithPalmer T. Tuning the Surface-Enhanced Raman Scattering Effect to Different Molecular Groups by Switching the Silver Colloid Solution pH. Appl Spectrosc. 2009; 63 (2): 214-3.

25. Smith-Palmer T, Douglas C, Fredericks P. Rationalizing the SER spectra of bacteria. Vib Spectrosc. 2010; 53 (1): 103-6. 